NASA urged to lay plans for mission to Europa

Tony Reichhardt, Washington

US planetary scientists are urging NASA to make a conventional mission to Jupiter's moon Europa a top priority.

The call has been spurred by increasing doubts surrounding the agency's plan to send a nuclear-powered craft to Europa and two of Jupiter's other satellites, Ganymede and Callisto.

The troubled Jupiter Icy Moons Orbiter (JIMO) is to be NASA's first nuclear-powered mission, but its launch date has already slipped from 2011 to 2015 , largely because of the novel technology involved.

Sensing trouble, a scientific advisory group for JIMO last month wrote to Andrew Dantzler, NASA's chief of Solar System exploration, to advise the agency to consider a conventionally powered Europa mission "if major slips beyond an expected JIMO launch in the 2015 time frame occur".

Along with Mars, Europa is seen as the most likely place in the Solar System to find extraterrestrial life. Robert Pappalardo, a planetary scientist at the University of Colorado in Boulder, is among some 80 scientists who have signed a white paper, attached to the JIMO advisory group's report, emphasizing the importance of Europa exploration. "We want to remind NASA that with or without JIMO, Europa is a top priority," Pappalardo says.

NASA surprised many scientists in 2003 by proposing JIMO as the first mission under its Project Prometheus nuclear-propulsion programme.

But JIMO has run into such problems (see Nature 431, 113; 2004) that NASA has ordered a comprehensive review of Prometheus, which should be complete in April. One option under consideration is to defer the Jupiter probe and begin the project with a smaller, more manageable nuclear mission, perhaps to our own Moon or to an asteroid.

No one is ready to declare JIMO dead just yet, but NASA is realizing that reaching Jupiter is "quite a big first step" for its nuclear programme, says Dantzler. He adds that he has already commissioned an informal study into a conventional mission to Europa. "I'm not putting a lot of money into it yet," he says. "But if it does come down to a conventional Europa mission, I want to hit the ground with the wheels already turning."

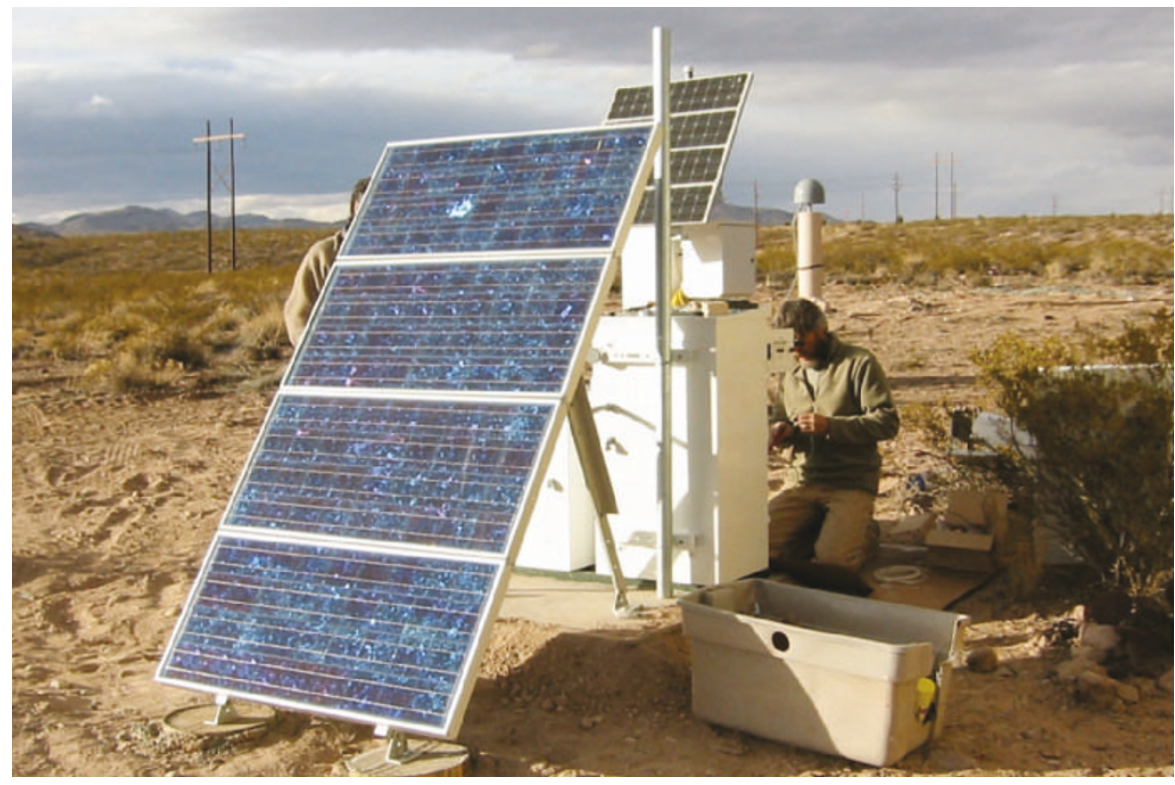

Ground force: researchers take readings from an EarthScope seismic station in Socorro, New Mexico.

\title{
Cash shortfall threatens to rock US geophysics project
}

Rex Dalton, San Diego

US Earth scientists fear that lack of funds could derail a megaproject to examine the geophysical structure of North America.

EarthScope, funded by the National Science Foundation (NSF), is designed to generate a three-dimensional view of the geophysical processes affecting Earth's mantle, tens of kilometres below the continent's surface. It should revolutionize scientists' understanding of volcanoes, fault systems and earthquakes.

Construction of the project's infrastructure is now into its second year, and involves some \$200-million worth of equipment. Although Congress authorized the NSF to buy and install the equipment over five years, it has delayed a decision on funding for the operation and maintenance - estimated at $\$ 13$ million per year - and the $\$ 100$ million required for research over the first decade of operations.

Approved in 2003, when the NSF's \$4.2billion annual research budget was expected to grow rapidly, EarthScope now faces a starkly different financial climate - the NSF's budget for the 2006 fiscal year is expected to be flat or even slightly reduced.

On 24 January, EarthScope submitted a 500 -page research plan for the coming years, including budget requests for operation and maintenance. EarthScope officials declined to discuss financial specifics, except to say that they were in line with earlier projections.

But there is no clear picture of the nearterm finances for individual research projects. Just \$4 million was available for EarthScope research this year, officials say. "People now are very nervous about the whole thing," says Adam Dziewonski, a seismologist at Harvard University who chairs a seven-strong advisory panel to the USArray, one of the project's components.

"The Earth science community's concern is merited. We need to work together to identify all available funding for research and operations," says the NSF's programme director for EarthScope, Kaye Shedlock.

EarthScope has three main components. The USArray is a mobile system involving more than 800 seismometers that will move east from California across the nation for a decade, visualizing the geophysical structure. The Plate Boundary Observatory (PBO) is a system of devices for examining tectonic plate interactions from Alaska to the lower states. And the San Andreas Fault Observatory at Depth (SAFOD) experiment will drill a core into the coastal mountains south of San Franicsco, installing pressure gauges and seismometers in the active fault zone to record movements and quakes.

USArray seismometers are now being deployed in California. SAFOD scientists have drilled more than $2.5 \mathrm{~km}$ deep, and plan to core into the fault this summer. $\mathrm{PBO}$ researchers are also preparing to set out equipment in Alaska this summer.

Gregory van der Vink, EarthScope's project director, acknowledges that there is concern in the geoscience community, but he is confident that the programme can secure the necessary research funds in the coming budget discussions. The goal is not just to put instruments in the ground and data in an archive, but to use them in research, van der Vink says. "We will do everything we can to win funds for research. This is the data set for the next generation of geoscientists," he adds. 